\title{
Hyperkalaemic periodic paralysis in pregnancy
}

\author{
Soon-Leong Yong, ${ }^{1}$ Teik-Hoy Sin, ${ }^{1}$ Eric Boon-Kiat Tang, ${ }^{2,3}$ Ming-Cheng Chai ${ }^{4}$
}

'Department of Obstetrics and Gynaecology, Sibu Hospital, Sibu, Sarawak, Malaysia ${ }^{2}$ Faculty of Medicine, SEGi University Sibu Clinical Campus, Sibu, Sarawak, Malaysia ${ }^{3}$ Department of Anaesthesiology, Sibu Hospital, Sibu, Sarawak, Malaysia ${ }^{4}$ Department of Obstetrics and Gynaecology, Sarikei Hospital, Sarikei, Sarawak, Malaysia

Correspondence to Dr Eric Boon-Kiat Tang, aerikh@gmail.com

Accepted 27 March 2018

Check for updates

To cite: Yong $\mathrm{S}-\mathrm{L}$, Sin $\mathrm{T}-\mathrm{H}$, Tang EB-K, et al. BMJ Case Rep Published Online First: [please include Day Month Year]. doi:10.1136/bcr-2017223588

\section{SUMMARY}

Hyperkalaemic periodic paralysis is a rare skeletal muscle disorder which is characterised by episodic muscle paralysis associated with hyperkalaemia. Although it is an autosomal-dominant disease, cases of de novo mutations have been reported. We report the case of a 30-year-old woman, gravida 5 para $3+1$, who was planned for an elective repeated caesarean section at 38 weeks and 3 days of pregnancy. She developed recurrent episodes of hyperkalaemic periodic paralysis after receiving corticosteroids. Intravenous calcium gluconate was administered to normalise potassium levels (from $6.3 \mathrm{mmol} / \mathrm{L}$ to $4.1 \mathrm{mmol} / \mathrm{L}$ ). Extra anaesthetic precautions were taken during the caesarean delivery. Postoperatively, she was well and discharged from the ward. She encountered similar symptoms in her third pregnancy, and there was no family history of muscle weakness which suggested a de novo mutation. Pregnancy seemed to result in vulnerability to hyperkalaemic attacks as she was never symptomatic outside pregnancy.

\section{BACKGROUND}

Hyperkalaemic periodic paralysis (hyperPP) is a rare entity of muscle weakness disease with a prevalence of 0.17 per $100000 .^{1}$ It is due to SCN4A gene mutation resulting in a defect in skeletal muscle sodium channels. ${ }^{2}$ Although it is an autosomal-dominant inheritance, cases of de novo mutations have been reported. ${ }^{2} 3$ Diagnosis of hyperPP is established based on a clinical history of muscle weakness, biochemical evidence of hyperkalaemia and a positive family history. ${ }^{2} 3$ HyperPP tends to be exacerbated by pregnancy due to oestrogenic influence. ${ }^{3}$ We report a woman with symptomatic hyperPP manifesting solely during pregnancy following exposure to triggering factors.

\section{CASE PRESENTATION}

A 30 -year-old woman, gravida 5 para $3+1$, at 38 weeks and 3 days of pregnancy was admitted for a planned elective repeat caesarean section (ERCS) in view of prior caesarean birth. Serum potassium was assessed preoperatively, and its level was $4.1 \mathrm{mmol} / \mathrm{L}$. The ERCS was scheduled prior to 39 weeks because she had no transport to the hospital the following week. Therefore, she received two doses of intramuscular dexamethasone, each $12 \mathrm{mg}$ at 12 hours apart, to reduce the risk of neonatal respiratory morbidity associated with the early ERCS. Twenty-one hours after the first dose of dexamethasone, she developed a sudden onset of bilateral lower limb weakness. A physical examination revealed normal consciousness and normal bilateral upper limb neurology but there was bilateral lower limb hypotonia. Serum potassium was $6.3 \mathrm{mmol} / \mathrm{L}$.

Retrospectively, in her third pregnancy (the year 2013) at 39 weeks' gestation, she had a sudden onset of bilateral lower limb weakness after banana intake. Despite the presence of hyperkalaemia (serum potassium level of $7.0 \mathrm{mmol} / \mathrm{L}$ ), the initial suspicion for Guillain-Barré syndrome was raised by the history of a preceding respiratory tract infection. Lytic cocktail (a combination of calcium gluconate, dextrose $50 \%$ and insulin) was administered, and the serum potassium normalised to $4.4 \mathrm{mmol} / \mathrm{L}$. Concurrently, an emergency caesarean section was performed, under spinal anaesthesia, for acute fetal distress. Postnatally, her lower limb weakness resolved spontaneously, and therefore the initially planned intravenous immunoglobulin therapy was withheld. She remained asymptomatic and her serum potassium levels were normal in the subsequent postnatal follow-ups.

In the current pregnancy (the year 2017), she was admitted to a district hospital at 34 weeks' gestation for threatened preterm labour, and a single course of antenatal corticosteroids was given to enhance fetal lung maturation. She then developed the second episode of muscle weakness with a serum potassium level of $7.6 \mathrm{mmol} / \mathrm{L}$. After two courses of lytic cocktails and inhalation of salbutamol, serum potassium normalised, and her muscle weakness resolved. The following weekly serum potassium levels were normal.

At the time of the attack, a diagnosis of hyperPP was made, though she had no family history of muscle weakness associated with hyperkalaemia. She was also managed by a multidisciplinary team consisting of obstetricians, physicians and anaesthetists. Intravenous calcium gluconate $10 \% 10 \mathrm{~mL}$ over 10 min was administered, and the serum potassium subsequently normalised to $4.1 \mathrm{mmol} / \mathrm{L}$. Oral hydrochlorothiazide $25 \mathrm{mg}$ daily was initiated to prevent the recurrence of hyperkalaemia.

\section{INVESTIGATIONS}

She was scheduled an appointment for genetic testing for mutation of SCN4A gene 6 weeks post partum. However, she did not turn up to the appointment and was not contactable.

\section{OUTCOME AND FOLLOW-UP}

The next day, caesarean section, under general anaesthesia using rocuronium (an aminosteroid, non-depolarising muscle relaxant) to facilitate endotracheal intubation as well as maintenance of optimal surgical conditions, was undertaken 
uneventfully without postoperative respiratory distress and malignant hyperthermia. The estimated blood loss was $700 \mathrm{~mL}$. She delivered a healthy infant girl weighing $2.65 \mathrm{~kg}$. Bilateral tubal ligation was undertaken for permanent sterilisation with her prior consent. After delivery, her bilateral lower limb weakness resolved. Her serum potassium levels were normal, and thus hydrochlorothiazide was stopped. Serum potassium levels remained normal in the postnatal follow-ups. Otherwise, she was never symptomatic outside pregnancy.

\section{DISCUSSION}

We reported a woman with an undiagnosed rare condition, presenting with multiple episodes of hyperPP during pregnancy. First, the diagnosis of hyperPP was missed during the first presentation because of disease rarity. Second, the history of preceding respiratory tract infection before the first episode of muscle weakness made the initial provisional diagnosis of Guillain-Barré syndrome more likely. Third, negative family history in this patient reduced the likelihood of the autosomal-dominant hyperPP during the initial evaluation, though this case was suggestive of de novo mutation. ${ }^{23}$

In this patient, the attacks of muscle weakness were provoked by potassium-rich food (banana) and steroids. Other triggering factors include alcohol, cold, fasting, emotional stress and strenuous exercise. ${ }^{3-5}$ Attacks tend to be more frequent and severe in pregnancy. ${ }^{3}$ Similarly, this patient experienced attacks only during pregnancy but remained asymptomatic outside pregnancy. This vulnerability could be attributed to oestrogenic influence as oestrogen levels increase throughout the pregnancy. ${ }^{3}$ Uncommonly, the beneficial effect of pregnancy on hyperPP disease severity, which is believed to be due to the beneficial mutations c.2111C > Tand p.T407M, has also been reported. ${ }^{67}$

The diagnosis of hyperPP is established based on the clinical presentation of muscle weakness or paralysis, hyperkalaemia and a positive family history. ${ }^{23}$ Negative family history suggests de novo mutation which was likely in this patient. Genetic testing to look for mutations in the SCN4 ionic channel gene is gold standard for the diagnosis of hyperPP but up to $20 \%$ of the cases would be tested negative for the gene mutation. ${ }^{2}$ In cases of diagnostic uncertainty, provocative tests such as a potassium challenge test can be employed but simultaneously carrying risks of triggering a severe attack. ${ }^{2}$ Muscle biopsy is generally not advisable as the findings are non-specific. ${ }^{2}$ For this patient, we were unable to determine the SCN4A gene mutation because she defaulted from the genetic testing. Thus, the diagnosis of hyperPP in this patient was made on clinical grounds on the basis of hyperkalaemia during muscle weakness attacks associated with provocative triggers.

As there is no curative treatment for hyperPP, treatment is merely symptomatic. Treatment for an acute attack is intravenous calcium gluconate and inhalation of salbutamol as was done in this case. ${ }^{23}$ Mild exercise or intake of carbohydrates may be helpful to relieve symptoms. Prophylactic measures such as avoidance of potassium-rich foods and medications, fasting, strenuous work and exposure to cold are equally important. ${ }^{23}$ Use of thiazide diuretics or a carbonic anhydrase inhibitor, such as acetazolamide could help to prevent attacks. ${ }^{23}$ However, the individuals' serum electrolytes should be monitored, and their serum potassium and sodium levels should not fall below $3.3 \mathrm{mmol} / \mathrm{L}$ and $135 \mathrm{mmol} / \mathrm{L}$, respectively. ${ }^{8}$ A potassium-lowering agent (eg, hydrochlorothiazide) was started in this patient to prevent any further attacks during perioperative periods.
Individuals with hyperPP are at risk of complications from surgery and anaesthetics. ${ }^{3}$ Non-anaesthetic surgical complications were reported in $22.8 \%$ of cases, including temporary complete paralysis postoperatively, respiratory difficulties and hyperthermia. Up to $29.9 \%$ of patients experienced attacks during general anaesthesia. During anaesthesia, non-depolarising muscle relaxants are preferred, ${ }^{23}$ for which, in this case, rocuronium was used. The use of depolarising muscle relaxants such as suxamethonium as well as anticholinesterase types of reversal agents should be avoided as there will be a risk of masseter spasm and respiratory muscle stiffness rendering endotracheal intubation and mechanical ventilation difficult. Perioperatively, maintaining normoglycaemia and normal body temperature are crucial to prevent attacks. Postoperatively, the affected patient needs to be closely monitored for signs of respiratory distress attributable to the disease itself, anaesthetic drugs that depress respiration and hypothermia. ${ }^{2}$ Our patient was managed as such, and she did not develop any of these complications. There is currently no agreed recommendation for the choice of regional or general anaesthesia for patients with hyperPP. In this particular case, as this patient was experiencing muscle weakness prior to the caesarean section, the choice for general anaesthesia was made based on the fact that if regional anaesthesia could have been administered, the anaesthetic team might not be able to distinguish whether the patient was having neurological deficit due to the underlying disease or if she could have suffered a complication from the regional anaesthetic technique such as spinal or epidural haematoma.

In conclusion, women with hyperPP are vulnerable to attacks of muscle weakness during pregnancy, especially following exposure to triggering factors. A multidisciplinary management is crucial for a successful pregnancy outcome.

\section{Learning points}

- Pregnant women with hyperkalaemic periodic paralysis (hyperPP) are vulnerable to muscle weakness attacks following exposure to triggering factors.

- Muscle weakness or paralysis associated with hyperkalaemia should raise strong suspicion of hyperPP, despite the absence of a family history as de novo mutation is still possible in this autosomal-dominant disease.

- HyperPP is not curable, and the management involves symptomatic treatment for acute attacks and prophylactic strategies to prevent future attacks.

- A multidisciplinary approach is ideal to achieve good pregnancy outcomes.

Acknowledgements The authors would like to thank the Director General of Health Malaysia for the permission to publish this case report, Prof Datu Dr Andrew Kiyu MBBS, MPH, DrPH, FACE, AM for critically reviewing this paper, and Dr TeckHock Toh, Head of Clinical Research Centre of Sibu Hospital, Sibu, Sarawak, Malaysia for encouragement and support.

Contributors S-LY, T-HS, EB-KT and M-CC contributed to conception, design, writing of abstract and case report.

Funding The authors have not declared a specific grant for this research from any funding agency in the public, commercial or not-for-profit sectors.

Competing interests None declared.

Patient consent Obtained.

Provenance and peer review Not commissioned; externally peer reviewed. (c) BMJ Publishing Group Ltd (unless otherwise stated in the text of the article) 2018. All rights reserved. No commercial use is permitted unless otherwise expressly granted. 


\section{REFERENCES}

1 Horga A, Raja Rayan DL, Matthews E, et al. Prevalence study of genetically defined skeletal muscle channelopathies in England. Neurology 2013;80:1472-5.

2 Weber F, Jurkat-Rott K, Lehmann-Horn F, et al. Hyperkalemic Periodic Paralysis. In: Pagon RA, Adam MP, Ardinger HH, GeneReviews. Seattle (WA: University of Washington, Seattle, 1993.

3 Charles G, Zheng C, Lehmann-Horn F, et al. Characterization of hyperkalemic periodic paralysis: a survey of genetically diagnosed individuals. J Neurol 2013;260:2606-13.

4 Finsterer J. Primary periodic paralyses. Acta Neurol Scand 2008;117:145-58.
5 Therby D, Guionnet B, Vaast P, et al. Gamstorp's disease and pregnancy. A case report. $J$ Gynecol Obstet Biol Reprod 1996;25:832-5.

6 Finsterer J. Disappearance of episodic weakness during pregnancy in hyperkalemic periodic paralysis from the SCNA4 mutation T704M. Neurologist 2009;15:289-90.

7 Finsterer J, Wakil SM, Laccone F. Pregnancy reduces severity and frequency of attacks in hyperkalemic periodic paralysis due to the mutation c.2111C >T in theSCN4Agene. Ann Indian Acad Neurol 2017;20:75-6.

8 Lehmann-Horn F, Rudel R, Jurkat-Rott K. Non-dystrophic myotonias and periodic paralyses. In: Engel AG, Franzini-Armstrong C, eds. Myology: Basic and Clinical. 3 ed. New York, NY: McGraw-Hill, 2004:1257-300.

Copyright 2018 BMJ Publishing Group. All rights reserved. For permission to reuse any of this content visit http://group.bmj.com/group/rights-licensing/permissions.

BMJ Case Report Fellows may re-use this article for personal use and teaching without any further permission.

Become a Fellow of BMJ Case Reports today and you can:

- Submit as many cases as you like

- Enjoy fast sympathetic peer review and rapid publication of accepted articles

- Access all the published articles

Re-use any of the published material for personal use and teaching without further permission

For information on Institutional Fellowships contact consortiasales@bmjgroup.com

Visit casereports.bmj.com for more articles like this and to become a Fellow 